\title{
Students' Adoption of Mobile Telephony in Higher Education Institutions: Understanding the Influencing Factors
}

\author{
Omotayo Kayode Abatan ${ }^{1}$, Nurudeen Ajayi ${ }^{2}$ \\ ${ }^{1}$ School of Computing,University of South Africa \\ ${ }^{2}$ Discipline of IS \& T, University of KwaZulu-Natal
}

\begin{abstract}
The universal telecommunications growth is largely attributed to rapid technological innovation and progressively more liberal policy environments. In the past, many developing countries implemented technical and legislative reforms that resulted in the increased adoption of telecommunications technology. This, in turn led to productivity improvements and the successful adoption of mobile telephony. The adoption of mobile telephony is influenced by many factors. This study identifies the factors that influence Information Technology (IT) students' perceptions on the adoption of mobile telephony and the quality of mobile telecommunication services for academic and social purposes at the University of KwaZulu-Natal (UKZN), Durban, South Africa. The findings suggests that students understand and are fully aware of the use of mobile telecommunication technology and its services as an important pedagogical tools in higher education institution. The understanding of the significance of the various factors influencing the adoption and usage of mobile telecommunication services by students engenders opportunities to explore ways through which mobile technology could be integrated into teaching and learning processes at higher education institutions. The integration of mobile telecommunication technology into teaching and learning at universities has been identified in this study as a practice that can facilitate student-centered learning.
\end{abstract}

\section{Introduction}

The introduction of the Global System for Mobile communications (GSM) technology by the European Union was criticized initially, but later turned out to be a productive decision. Today, GSM technology has been adopted as a standard and boasts penetration rates never been reached before by any other technology [1]. Within a decade of the introduction of the standard, the number of mobile telecommunication subscribers grew from less than one billion to almost four billion worldwide between 1996 and 2006 [2]. Today, the number of mobile telecommunication subscribers has extended to an estimate of 7.4 billion.
The Universal Mobile Telecommunications System (UMTS) or 3G over GSM (2G mobile technology) succeeded GSM and played a significant role in the mobile telecommunication industry. In the modeling of the 3G, Time Division Multiple Access (TDMA) was substituted with Code Division Multiple Access (CDMA), which supports the highest bandwidth of $2 \mathrm{Mbps}$, and it is said to be sufficient for future mobile telecommunication loads [3]. However, the industry continues to evolve with 4G and now 5G being mooted as the latest incarnations of mobile telecommunications. As a result, the mobile telecommunication industry has experienced tremendous growth and rapid structural change.

This study reviewed several academic literature on the factors that influence the adoption of mobile technology. The study further draws from students' articulation of the quality of service they received, the significance of the factors and the relevance of mobile telecommunication services for their academic and social activities. In what follows, the paper discusses the models that anchors the study. Literature review on the factors influencing mobile telephony adoption is presented, followed by the research design and findings. The final sections of this paper presents the discussion of findings and concludes the study with recommendations for the integration of mobile technology into teaching and learning activities in higher education institutions.

\section{Theoretical framework and trends}

Numerous studies have used the Technology Acceptance Model (TAM) and Theory of Planned Behaviour (TPB). In this study TAM was used as it suggests that attitude would be a direct predictor of the intention to use technology which would in turn impact upon the actual usage of the technology. However, Davis and Venkatesh deemphasized the significance of attitude as a determinant of the use of technology but argue that perceived usefulness and perceived ease of use are critical factors that influence the use of technology [4].

The theory of planned behaviour is also used to understand people's intention to engage in a number 
of activities. Some of the activities, which includes the use of mobile telecommunication services for academic and social activities, were described in Siragusa and Dixon's [5] study.

The perceptions of users around the world on the use of technology are reviewed in this section of the research. In Saudi Arabia, Al-Fahad [6] analysed students' attitudes and perceptions towards the effectiveness of mobile learning with the use of quantitative survey to focus on the importance of mobile learning and teaching in university environment. It is understandable that students' perception of mobile learning may be influenced by certain distinct variables. Such variables considered in this study were experiences, perceptions and attitudes to the technology. These variables are drawn parallel to that of Al-Fahad's survey mentioned above which considered gender, course of study and attitudes to new technology.

Numerous studies carried out around the world have used technology acceptance model and theory of planned behaviour to support the strength and credibility of their research. TAM was considered to strengthen this study as it suggests that attitude would be a direct forecaster of the intension to use technology which would in turn predict the actual usage of the technology [4]. Bertrand and Bouchard applied TAM in the study on the acceptance of virtual reality (VR) with people who are favourable to its use. Standard items were adapted to test the TAM and added perceived cost factor which facilitated the role on intension to use the technology. TAM was adapted to identify, in an empirical method, the elements that play a role on the intension to use or not to use the technology in the study.

To sum up, Chen et al. also applied the combination of TAM and innovation diffusion theory (IDT) to examine consumer behaviour in the virtual-store context. Their findings stipulated that the primary determinant of consumer attitudes towards using virtual-stores were compatibility, perceived usefulness and perceived ease of use. This study has chosen to follow the line of evaluation to further provide additional understanding to the role of environmental factors: experience, perceptions, attitudes, intension to use, perceived usefulness and ease of use of mobile telecommunication services amongst first-year IT students in UKZN. Therefore, technology acceptance model and theory of planned behaviour were selected as the theories of choice.

\section{Literature review}

User satisfaction with mobile telecommunication services can be achieved by many factors. These factors include but not limited to: Cost, Call quality, Security, Network availability and value. However, the most important determinant of satisfaction is the user's own perceptions [5]. The use of technology applications is enhanced if the application navigation and content delivery reflects the user's needs, operate within a trustworthy environment and are user-friendly. The following subsections presents a literature review on the identified factors:

\subsection{Cost/Billing services}

The integration of the internet with mobile telecommunication services has modified existing business models in such a way that network operators and service providers are able to control the cost sharing of services [7]. Various companies (i.e., mobile telecommunication companies) lay down their own functional components for billing and charging users or subscribers utilizing their services. Mobile telecommunication operators traditionally target urban areas, nevertheless the rate at which mobile phones are demanded from rural and low-income areas in Africa have exceeded all expectations. For instance, in 1999, Nigeria's minister of communication promised that cellphone services will be an affordable universal access to the nation. The challenge, however, was "whether the rural-poor of the country will be able to afford cellphone services if it is made available? If they cannot, then the affordable universal access cannot be achieved" [8]. Which thus means that, liberalization and privatization that are said to be the drive to lessen prices and enhance mobile telecommunication services available to users, might not be easily achievable as well.

\subsection{Customer care services}

It is not easy to satisfy customers/users, but as long as customers indicate a satisfied response, the company-customer relationship can be assumed to be strong. In searching for new product ideas, it is logical to first consider customer's needs, wants, preferences, attitudes, lifestyles and so on. Zeithaml and Bitner defined customer service as a set of activities designed to enhance the feeling that a product or service has met customer's expectation [9]. The link between customer satisfaction and service quality creates value and help the customer to make a decision whether the service justifies its cost.

\subsection{Network availability}

The mobile telecommunications market is driven by the rapid development in technology and by the demand from users. Mobile technology development has changed the pattern in which mobile telecommunication offers services, from voice oriented communication to a mixture of data and multimedia services [10]. The availability of network 
to users has become one of the major factors considered when networks are being designed.

Network availability is referred to as the network's ability to respond to the request made by those accessing or using the network. The availability of mobile network is the actual percentage of the available total network bandwidth to transmit the traffic. Hence, there should be enough available spare bandwidth to retransmit the traffic without any reduction in performance.

\subsection{Network stability}

Oggerino [11] described the percentage method for describing the availability of a network. The essential use of the availability percentage is to figure out how much downtime the user has over a year-long period. Network user's downtime is determined by multiplying the number of minutes in a year by the percentage of availability. This gives the minute per year the user will be operational. The balance is the downtime user can expect. The convergence of mobile telephony and the Internet has become a part of our lives; people are dependent on them to carry out their personal, social and business activities. People rely on them and thus, people also need them to be highly reliable, in other words, the networks must work all the time (i.e., network must be highly stable).

\subsection{Security}

When subscribers communicate using mobile telecommunication networks, there is much data generated which needs to be handled in a much secured way. Security measures such as authentication, encryption and non-repudiation are very important aspects of mobile telecommunication network management [12]. These security measures must be able to protect unauthorized operations on the network but still grant access to numerous users or devices. Protection of confidentiality, integrity and availability are the major requirements that public mobile telecommunication networks should offer for the security of data. In addition to this, a user's location needs to be also protected.

Due to the historic trust relationship between mobile telecommunication network operators with their users, which involves the protection of subscribers' data and billing services and the relative absence of spam in voice telephone network services, it is believed that all public mobile telecommunication network operators currently have advantage over web companies and other new entrants. Many companies have failed not just for poor services and products or even lack of capital but rather failed because of their failure to conform to acknowledged standards or legitimacy [13]. Organizations that conform to legitimacy pressure, therefore, survive longer in an environment than the organizations that do not conform.

\subsection{User satisfaction}

With mobile telecommunication, users' satisfaction is attained if the users are able to reach out to the people they want at a particular time. Does user satisfaction positively influence customer loyalty? It is not always a sufficient condition because in a number of cases, user satisfaction have been found to be unsuccessful in producing the likely effects on the market. Therefore, future researchers should consider analyzing other potential influencing factors of user satisfaction. In addition, switching barriers perform the function of an adjustment variable in the relationship between customer satisfaction and loyalty. Switching behaviour can be articulated as the process of being loyal to one service provider and switching to another service provider due to dissatisfaction or any other problem in service quality [14]. Sathish et al. further explained that even if a customer is loyal to a particular service provider and the service provider does not satisfy the customers' needs, the costumers switch to a competitor brand. However, switching may incur some cost. Switching cost is defined as the mental and physical cost users encounter as well as the economic costs they face when changing network provider [14].

\section{Methodology}

The data for this paper was generated from research conducted amongst first-year IT students at the Westville campus of the University of KwaZuluNatal. A 50\% simple random sample was drawn from the 945 first-year IT students at UKZN. A total of 313 questionnaires were returned.

The self-administered questionnaire consisted of structured, closed format, biographical and rating scale type questions. The format of the questionnaire elicited information about the relevant issues on the use and adoption of mobile telecommunication services amongst first-year IT students in UKZN. The data and information collected were prestructured according to the assumed relationship between the concepts of the models used. Quantitative research method was adopted and data analysis using set of statistical techniques for data diagnosis such as data preparations, data descriptions and scale analysis was carried out. A descriptive and inferential analysis was used to analyze the collected data. Basic features of the collected data were described and interpreted. A combination of statistical software Statistical package for Social Sciences (SPSS) and Microsoft Excel were used for the data analysis. 


\section{Research findings}

\subsection{Background information}

A total of 313 first-year IT students in UKZN participated in the study. In this section, background information of participants in UKZN is presented in relation to gender, age and race.

5.1.1. Gender. There were more female participants than males. Male students constituted $41.35 \%$ and female students constituted $58.65 \%$.

5.1.2. Age. A sizable number $-65.7 \%$ of participants - were within the age bracket of 19-24, followed by students below 18 years of age at $31.7 \%$. Participants within the age bracket of 25-29 constituted $1.6 \%$.

5.1.3. Race. $56.5 \%$ of participants were Indians, $39.4 \%$ were Africans, Whites and Coloured had the same percentage component of $1.6 \%$ each. $0.3 \%$ of participants indicated "Another group" while $0.6 \%$ did not indicate their race.

\subsection{Mobile telecommunication network operators}

At the time of data collection, South Africa had four major mobile telecommunication operators namely Cell C, MTN South Africa, Virgin Mobile and Vodacom. Other major mobile telecommunication operators (Redbull mobile and 8ta) were launched after the completion of the fieldwork. This section identifies the mobile telecommunication network operators that first-year IT students at UKZN subscribed to out of the four major ones at the time of the study.

The data shows that $42.1 \%$ of participants subscribed to Vodacom, $34.7 \%$ to MTN South Africa, $19.9 \%$ to Cell C, and $0.6 \%$ to Virgin Mobile. Some of the participants subscribed to more than one mobile telecommunication network operator. It was gathered that $1.6 \%$ of participants subscribed to both Vodacom and MTN South Africa, $0.6 \%$ to MTN South Africa and Cell C, and $0.3 \%$ to Vodacom and Cell C. Differentiations in mobile telecommunication services and cost accounted for subscription to more than one network.

\subsection{Students' perceptions of mobile telephony adoption}

It is acknowledged that mobile telecommunication network operators may experience problems that disrupt or make the provision of services difficult. The frequency of such problems may affect user satisfaction and even the fortunes of the operator. They also test the loyalty of users to the network operator. To assess the response and impact of such problems, students were asked to specify what action they would take during cases of persistent poor quality services. Figure 1 presents the responses to that question.

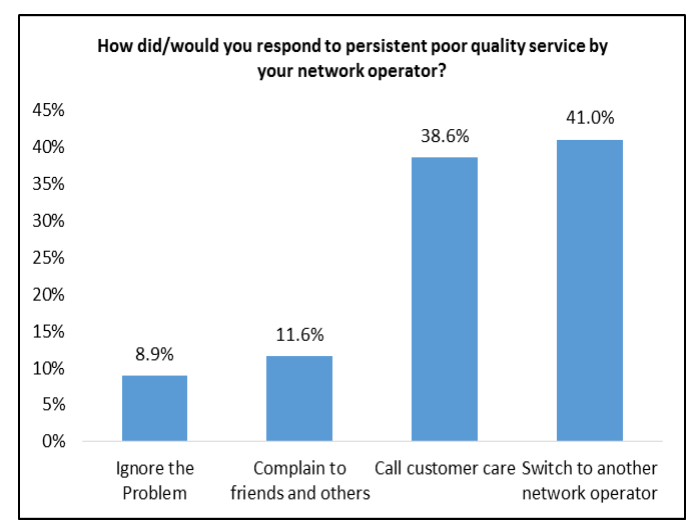

Figure 1. Distribution of Persistent Poor QoS by Network Operators

A small number of participants at $8.9 \%$ indicated that they would ignore the problem. This presupposes that these participants would do nothing about persistent poor quality services. In the view of others $(11.6 \%)$ reaction to persistent poor quality service would take the form of complaints to friends. The highest number of participants constituting $41 \%$ indicated that they would switch to another network operator. This implies that persistent poor quality service by network operators potentially undermines user loyalty and induces change from one network to another that is perceived as less riddled with servicerelated problems.

Another group of participants $(38.6 \%)$ would call customer care centre to report persistent service related problems rather than switch from one network operator to another. Whatever the action taken by users it is evident from the study that persistent poor quality service elicits a reaction that does not project a positive image of the network operator.

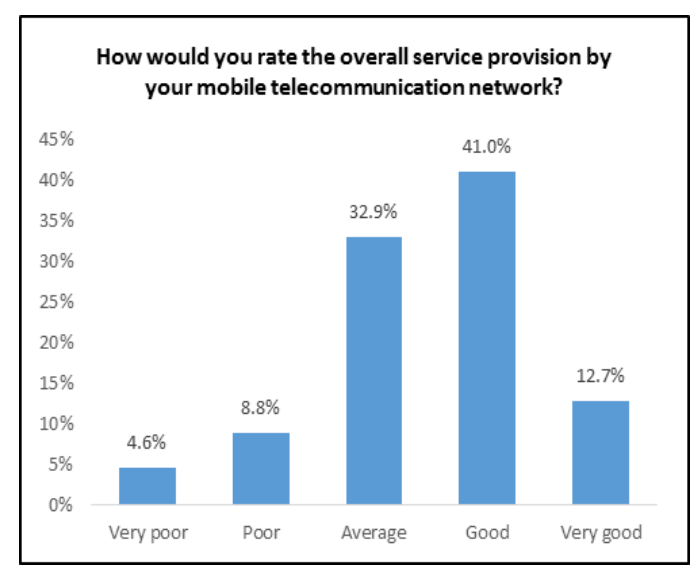

Figure 2. Distribution of Overall Service Provision 
Drawing from the high quality rating of specific mobile telecommunication services as well as comparatively lower number of participants experiencing challenges, it is not surprising that significantly fewer participants (as shown in the figure above) described the overall service provision by mobile telecommunications networks as very poor $(4.6 \%)$ and poor $(8.8 \%)$, which suggests that the overall service provision is deemed to be good.

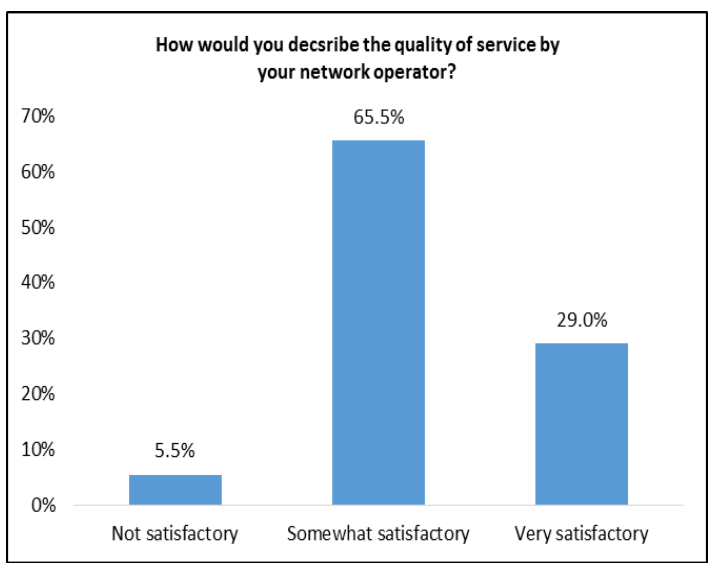

Figure 3. Distribution of QoS by Network Operators

In view of the generally positive rating of service provision, Figure 3 indicated that most participants found the quality of service by their network operator to be somewhat satisfactory $(65.5 \%)$ or satisfactory $(29 \%)$. A tiny fraction of participants $(5.5 \%)$ described the quality of service by their network operator as not satisfactory.

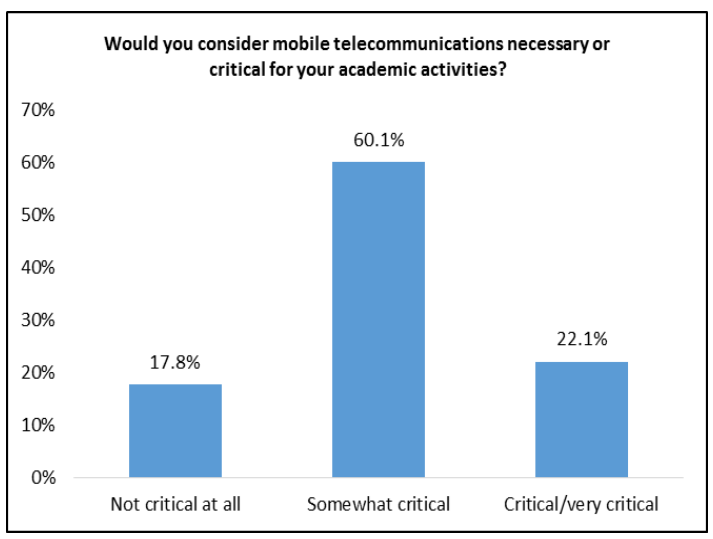

Figure 4. Relevance of Mobile Telecommunications to Aacademic Activities

Students were asked to state the extent to which they considered mobile telecommunication services as critical to their academic activities. This question was intended to find out if participants recognized the value or relevance (if any) of mobile telecommunication services to the performance of academic work. In other words, do mobile telecommunication services lend themselves to the execution of academic tasks? This question is considered necessary because it is essential to find out how students in IT-related disciplines think about the interface between technology and education. In this case, students had the opportunity to indicate the relevance of mobile telecommunication services to academic activities.

Figure 4 (above) presents participants' understanding of the extent to which mobile telecommunication services are critical to the performance of academic activities. More than half of the number of participants $(60.1 \%)$ considers mobile telecommunications as somewhat critical or necessary for academic activities. A group of students constituting $22.1 \%$ of participants consider mobile telecommunications as critical or very critical for academic activities. On the other hand, $17.8 \%$ of participants indicated that mobile telecommunications were not critical or necessary at all for academic activities. The overarching perception is that mobile telecommunications offer some utility to the performance of academic tasks. Hence, there is recognition or acknowledgement of the usefulness of mobile telecommunications in teaching and learning.

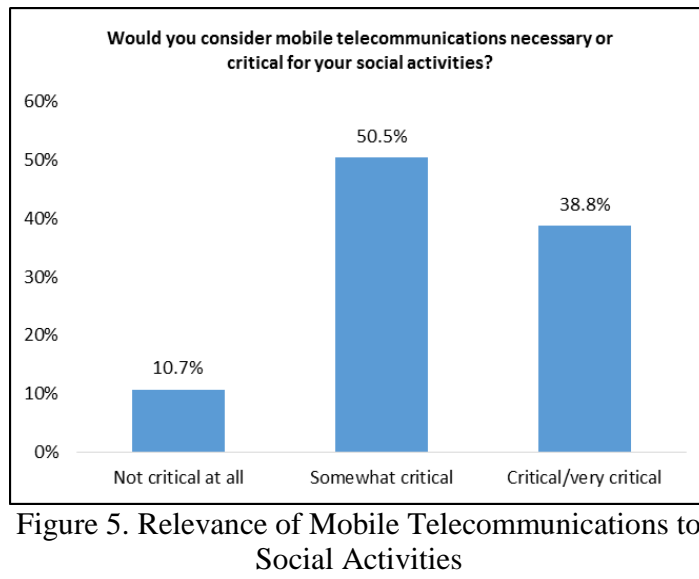

The question as to the necessity of mobile telecommunication services to social interactions was posed to establish the relevance that participants attached to technology in enhancing social life. Figure 5 shows how participants perceive mobile telecommunications as critical or not to social activities. The highest percentage of students $(50.5 \%)$ thought that mobile telecommunications were somewhat critical for social activities. Another $38.8 \%$ of participants deemed mobile telecommunications as critical or very critical for social activities. The third category of students representing $10.7 \%$ of participants felt that mobile telecommunications were not critical at all. The dominant view is that mobile telecommunications were necessary or critical for social activities. The preponderance of opinion in the direction of positive correlation between mobile telecommunications and social activities is shown in figure 5 . 


\section{Discussion of findings}

To validate the opinions of participants about their responses to poor quality of service by network operators (i.e. persistent poor quality of service), ZTests was conducted to test the proportion of the responses with the most frequencies: call customer care and switch to another network, depicted in Table 1 and 2.

Table 1. Frequency results on persistent poor quality services by network operator

\begin{tabular}{|l|l|r|r|r|r|}
\hline \multicolumn{5}{|c|}{ How did/would you respond to persistent poor quality service by your network operator? } \\
\hline & & Frequency & Percent & Valid Percent & $\begin{array}{c}\text { Cumulative } \\
\text { Percent }\end{array}$ \\
\hline Valid & Ignore the problem & 26 & 8.3 & 8.9 & 8.9 \\
\hline & Complain to friends and others & 34 & 10.9 & 11.6 & 20.5 \\
\hline & Call customer care & 113 & 36.1 & 38.6 & 59 \\
\hline & Switch to another network operatoo & 120 & 38.3 & 41 & 100 \\
\hline & Total & 293 & 93.6 & 100 & \\
\hline Missing & System & 20 & 6.4 & & \\
\hline Total & & 313 & 100 & & \\
\hline a. Location = Durban & & & & \\
\hline
\end{tabular}

Table 2. Proportion Table for call customer care and switch to another network

\begin{tabular}{|l|l|l|l|}
\hline & Total & Frequency & Proportion \\
\hline Call Customer Care & 293 & 113 & $38.6 \%$ \\
\hline $\begin{array}{l}\text { Switch to another } \\
\text { network }\end{array}$ & 293 & 120 & $41.0 \%$ \\
\hline Overall & 586 & 133 & $39.8 \%$ \\
\hline
\end{tabular}

H0: The two proportions are equal

$\mathrm{H} 1$ : the two proportions are not equal

$$
Z=\frac{P_{\text {switch }}-P_{\text {Call }}}{\sqrt{\hat{p}(1-\hat{p})\left(\frac{1}{n_{1}}+\frac{1}{n_{2}}\right)}}=\frac{0.41-0.386}{\sqrt{0.398 \times 0.602\left(\frac{1}{293}+\frac{1}{293}\right)}}=0.593
$$

The critical $Z$ value at the $5 \%$ significance level is 1.96 so H0 is NOT rejected since the test statistic is smaller than the critical value. The two proportions are NOT significantly different

The following Tables 3 and 4 present the Z-Tests that was conducted on the results obtained about participants' ratings of the overall experience on service provision by mobile telecommunication network provider.
Table 3. Frequency Results on the rating of overall service provision by network operator

\begin{tabular}{|l|l|r|r|r|r|}
\hline \multicolumn{5}{|c|}{ How would you rate the overall service provision by your mobile telecommunication network? } \\
\hline & & \multicolumn{1}{l|}{ Frequency } & \multicolumn{1}{l}{ Percent } & Valid Percent & $\begin{array}{c}\text { Cumulatuve } \\
\text { Percent }\end{array}$ \\
\hline Valid & Very poor & 14 & 4.5 & 4.6 & 4.6 \\
\hline & Poor & 27 & 8.6 & 8.8 & 13.4 \\
\hline & Average & 101 & 32.3 & 32.9 & 46.3 \\
\hline & Good & 126 & 40.3 & 41 & 87.3 \\
\hline & Very good & 39 & 12.5 & 12.7 & 100 \\
\hline & Total & 307 & 98.1 & 100 & \\
\hline Missing & System & 6 & 1.9 & & \\
\hline Total & & 313 & 100 & & \\
\hline a. Location = Durban & & & & \\
\hline
\end{tabular}

Table 4. Proportion table for average and good results

\begin{tabular}{|c|c|c|c|}
\hline & Total & Frequency & Proportion \\
\hline Average & 307 & 101 & $32.9 \%$ \\
\hline Good & 307 & 126 & $41.0 \%$ \\
\hline Overall & 614 & 227 & $36.97 \%$ \\
\hline
\end{tabular}

H0: The two proportions are equal $\mathrm{H} 1$ : the two proportions are not equal

$$
Z=\frac{P_{\text {Good }}-P_{\text {Average }}}{\sqrt{\hat{p}(1-\hat{p})\left(\frac{1}{n_{1}}+\frac{1}{n_{2}}\right)}}=\frac{0.41-0.329}{\sqrt{0.369 \times 0.631\left(\frac{1}{307}+\frac{1}{307}\right)}}=2.097
$$

The critical $Z$ value at the $5 \%$ significance level is 1.96 so H0 is rejected. The two proportions are significantly different.

To probe the opinions of participants about the quality of mobile telecommunication services, participants were required to indicate the significance of factors that are thought to influence the adoption of mobile technology.

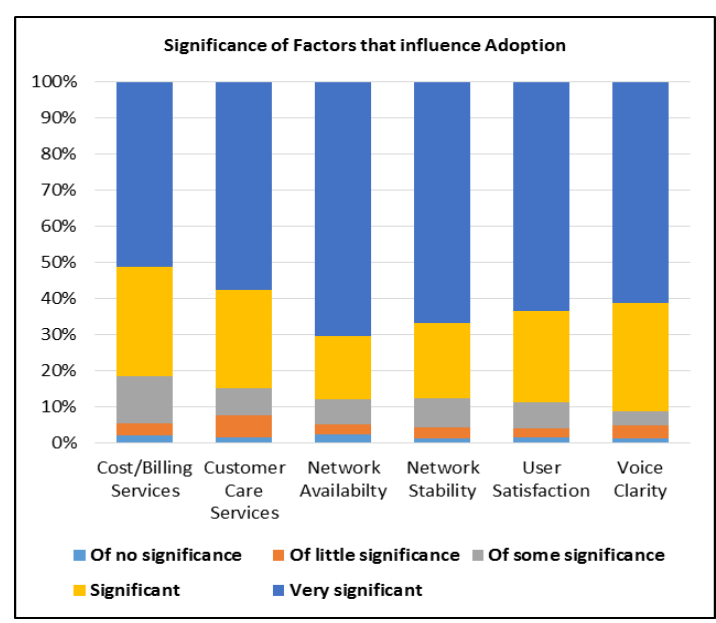

Figure 6. Significance of Factors that Influence Mobile Telephony Adoption

The responses presented in figure 6 shows that each factor is very significant to influence the adoption of mobile telephony. The results show that 
the percentage of all factors (Cost/Billing Services, Customer Care Services, Network Availability, Network Stability, User Satisfaction and Voice Clarity) was higher than $50 \%$. It is an indication that participants perceived these factors as critical to their use of mobile technology and their potential to enhance or undermine their academic or social agendas.

\section{Conclusion}

Findings in terms of experiences and perceptions of students regarding their use of mobile technology and the factors that influence the adoption of mobile technology for academic and social purposes suggests that students understand and are fully aware of the use of mobile telecommunication services. The use of the technology is self-defined or at the discretion of students (i.e. students are at liberty to use or not to use the technology). The varying ratings of quality of service (QoS) provided by network operators and the relevance of mobile telecommunication services for academic and social activities to students could serve as important pedagogic tools.

The understanding of the significance of the various factors influencing the adoption and usage of mobile telecommunication services by students engenders opportunities to explore ways through which mobile technology could be integrated into teaching and learning processes at higher education institutions. The integration of mobile telecommunication technology into teaching and learning at universities will be important in facilitating student-centered learning.

\section{References}

[1] L. Fuentelsaz, J. P. Maicas and Y. Polo, The evolution of mobile communications in Europe: The transition from second to third generation. Telecommunication Policy, 2008, pp. 436-449.

[2] C. Djiofack- Zebaze and A. Keck, Telecommunications Services in Africa: The Impact of WTO Commitments and Unilateral Reform on Sector Performance and Economic Growth. World Development. Vol. 37, No. 5, 2009, pp. 919-940.

[3] H. H. Ou, M. S. Hwang and J. K. Jan, A simple Mobile Communication Billing System among Charged Parties. Applied Mathematics and Computation 192, 2007, pp. 487-495.

[4] F. D. Davis, R. P. Bagozzi and P. R. Warshaw, User Acceptance of Computer Technology: A Comparison of Two Theoretical Models*. Management Science, 985, 1989.

[5] L. Siragusa and K. C. Dixon, Planned Behaviour: Student Attitudes towards the Use of ICT interactions in Higher Education. Proceedings Ascilite Melbourne,
Bently, Sydney. Curtin University of Technology, 2008, pp. 942-953.

[6] F. N. Al-Fahad, Students' Attitude on Perceptions towards the Effectiveness of Mobile Learning in King Saudi University, Saudi Arabia. Turkish Online Journal of Educational Technology, Vol. 8, No. 2, Article 10, 2009, pp.111-119.

[7] M. Koutsopoulou, A. Kaloxylos, A. Alonistioti and L. Merakos, A platform for charging, billing, and accounting in future mobile networks. Computer Communications 30, 2007, pp. 516-526.

[8] C. Onwumechili, Dream or Reality: Providing Universal Access to Basic Telecommunications in Nigeria? Telecommunications Policy 25, 2001, pp. 219231.

[9] V. A. Zeithaml and M. J. Bitner, Services Marketing: Integrating Customer Focus across the Firm. Boston: McGraw-Hill Irwin, 2003.

[10] M. K. Kim, M. C. Park and D. H. Jeong, The Effects of Customer Satisfaction and Switching Barrier on Customer Loyalty in Korean Mobile Telecommunication Services. Telecommunications Policy 28, 2004, pp. 145159.

[11] C. Oggerino, High Availability Network Fundamentals. Indianapolis, USA: Cisco Press, 2001.

[12] SUN, Telecom Network Management with Enterprise JavaBeans Technology. Palo Alto: SUN Microsystems, Inc., 2001.

[13] B. Low and W. Johnston, Securing and Managing an Organization's Network Legitimacy: The case of Motorola China. Industrial Marketing Management Vol. 37, 2008, pp. 873-879.

[14] M. Sathish, K. S. Kumar and K. J. Naveen, A Study on Consumer Switching Behaviour in Cellular Service Provider: A Study with Reference to Chennai. Far East Journal of Psychology and Business, Vol. 2, No. 2, 2011, pp. 71-81. 